\title{
Prevalence of workplace violence in Northwest Ethiopia: a multivariate analysis
}

\author{
Bewket Tadesse Tiruneh ${ }^{1 *}$, Berhanu Boru Biffu1', Akililu Azazh Tumebo², Mengistu Mekonnen Kelkay', \\ Degefaye Zelalem Anlay ${ }^{1}$ and Berihun Assefa Dachew ${ }^{3}$
}

\begin{abstract}
Background: Workplace violence has been acknowledged as a global problem, particularly in the health sector. However, there is scarce data on workplace violence among nurses in Ethiopia. The aim of this study was to assess the prevalence of workplace violence and associated factors among nurses in northwest Ethiopia.

Methods: Hospital based cross-sectional study design was employed in 386 nurses from April 1 - April 30, 2015. Data were collected through the use of self-administered questionnaire developed by the International Labor Office/International Council of Nurses/World Health Organization and Public Services International. To keep the quality of the data collection training was given to supervisors and data collectors. Piloting was done in Debark hospital two weeks before actual data collection to assess the tool's clarity and make amendments. The proposal was approved by the Institutional Review Board of University of Gondar prior to study commencement and a written consent was obtained from each study participant.
\end{abstract}

Results: The overall prevalence of workplace violence was $26.7 \%$. Exploratory logistic regression analyses suggested that age, number of staff in the same work shift, working in a male ward, history of workplace violence, and marital status were factors independently associated with workplace violence

Conclusion: The prevalence of workplace violence among nurses was high. Creating a prevention strategy involving different stakeholders is recommended.

Keywords: Hospital, Nurse, Prevalence, Factors, Workplace violence

\section{Background}

The definition of workplace violence is: "Incidents where staff are abused, threatened or assaulted in circumstances related to their work, including commuting to and from work, involving an explicit or implicit challenge to their safety, well being or health" [1].

It includes physical and Psychological violence which is a trauma to the victim caused by acts or coercive tactics that includes humiliating the victim, controlling what the victim can and cannot do, withholding information from the victim, deliberately doing something to make the victim feel diminished or embarrassed, isolating the victim from friends and family, and denying the victim access to money or other basic resources [2].

\footnotetext{
* Correspondence: jeryfiker21@gmail.com

${ }^{1}$ University of Gondar, College of Medicine and Health Science, School of

Nursing, P.O. Box: 196, Gondar, Northwest Ethiopia

Full list of author information is available at the end of the article
}

Currently, workplace violence is a widespread problem in the health sector and all health professionals are at a high risk. Gradually, it is becoming a fundamental human rights issue with its negative effect on the achievement of organizations. It affects all sectors and now it is rapidly spreading in the health care setting [3].

In 2013, the Bureau of Labor Statistics (BLS) in the USA reported that workplace assaults ranged from 23,540 and 25,630 annually from which more than $70 \%$ of these were in healthcare and social service settings. Health care and social service workers are almost four times as likely to be injured as a result of violence as the average private sector worker [4].

Violence against healthcare workers is a well-known problem in the United States of America [5]. For instance in Minnesota non-fatal physical assault and nonphysical forms of violence are frequent among nurses. 
Such violence were 13.2 and $38.8 \%$ respectively and mostly they were perpetrated by patients or clients [6].

In addition to physical injury, disability, chronic pain, and muscle tension, nurses who experience violence suffer psychological problems such as loss of sleep, nightmares, and flashbacks as well as short term and long-term emotional reactions, including anger, sadness, frustration, anxiety, irritability, apathy, self-blame, and helplessness. This all can have a direct or indirect relationship with work productivity [6-8]

Today hospital violence against health care providers, especially in nurses, is a major worry in the health care environment, but the actual magnitude of the problem is unknown [9]. In sub-Saharan African countries, nurse reported one or more levels of violence, including physical violence [10]. There is an increasing concern about workplace harassment in South Africa [11].

There is impressive progress of violence in health care service of east African countries; it is tremendously rising among nurses that are highly affected by this vice. Health workers experience different forms of violence both physical and psychological with common forms of violence, including verbal abuse, threats, assault, bullying and harassment. Realities such as staff shortages and increased patient acuity create substantial barriers to eliminating violence [12].

In Ethiopia, researchers showed that nurses had a history of verbal abuse, sexual harassment, bullying/mobbing and physical violence in the past [13]. Therefore, this study was conducted to establish the prevalence and factors associated with workplace violence among nurses working in the referral hospitals of Amhara Regional State, Ethiopia.

\section{Methods}

A hospital based cross-sectional study design was used from April 1 - 30/2015 in three public referral hospitals of Amhara regional state Ethiopia. These were University of Gondar Teaching and Referral Hospital, Felege Hiwot referral hospital, and Deberberhan referral hospital. For each site, the catchment population is estimated to be 7 million people. There were about 800 nurses working in these hospitals. All sampled nurses meeting inclusion criteria and working in the selected study hospitals were included. A single population proportion formula was used to determine the sample size. Assuming a $95 \%$ confidence level, $5 \%$ margin of error and $23.3 \%$ of prevalence [13], the required sample size was at least 292 participating nurses. This sample size was allocated proportionally. Systematic random sampling techniques were used to select participants and participants were asked about their workplace violence experiences for the last 12 months and data were collected using a self-administered questionnaire which was adapted from the International
Labor Office/International Council of Nurses/World Health Organization/Public Services International on Workplace Violence in the health sector. The questionnaire was modified in order to meet the local language. To maintain data quality, training was given to data collectors and supervisors. In addition, the questionnaire was pilot tested in $10 \%$ of the total sample size to identify potential problematic areas in Debark Hospital before the actual data collection. Supervision was carried out on daily basis during the data collection to check completeness and consistency of the data both by the supervisor and principal investigator.

\section{Data analysis}

The collected data were entered and cleaned using EPI INFO and analyzed using IBM SPSS Statistics version 20. Frequency distributions and percentages were calculated to describe socio demographic characteristics. Simple and multiple logistic regression analyses were used to explore associations between workplace violence and participant characteristics (working in male ward before, working in male ward now, waiting long time to receive health care, having workplace safety training, availability of enough supplies in the hospital, history of reporting workplace violence,providing community service, having training on anger management, working in the night shift, working any time between 7:00 and 18:00, educational level, sex of the participants, sex of the patient working with, marital states, service year, working in a specific specialties, the number of staff during the same working shift, age of the participants and monthly income). Odds ratios and $95 \%$ confidence intervals were used as measures of association. In an effort to identify characteristics independently associated to workplace violence, an exploratory multivariable logistic model was fitted with the characteristics that were individually associated with workplace violence at the 0.2 significance level. Predictors with $p<0.05$ in the model were considered suggestive of being independent predictors of workplace violence. No correction for multiple testing was conducted due to the exploratory rather than confirmatory objective of the analysis.

\section{Results \\ Socio-demographic characteristics of the study population}

Out of 428 study participants, 386 nurses were participated in the study giving a response rate of $90.2 \%$. The more than half of the study participants were male 220 [57 \%] and 247 [64\%] of them were single. Over threefourths of the participants were BSc on their educational status [84.5\%]. Nearly half (49.7\%) of the participants have between 1 and 5 years of employment in the hospital (Table 1). 
Table 1 Socio-demographic characteristics of respondents, Amhara Regional state Referral Hospitals Ethiopia, $2015(n=386)$

\begin{tabular}{|c|c|c|c|}
\hline Variables & & Frequency & $\%$ \\
\hline \multirow[t]{4}{*}{ Age in years } & $10-29$ & 276 & 71.5 \\
\hline & $30-39$ & 70 & 18.1 \\
\hline & $40-49$ & 25 & 6.5 \\
\hline & $>50$ & 15 & 3.9 \\
\hline \multirow[t]{2}{*}{ Sex } & Male & 220 & 57 \\
\hline & Female & 166 & 43 \\
\hline \multirow[t]{3}{*}{ Marital status } & Single & 247 & 64 \\
\hline & Married & 21 & 5.4 \\
\hline & Divorced/Separated & 118 & 30.6 \\
\hline \multirow[t]{4}{*}{ Income/\$ USD } & $<117.5$ & 56 & 14.5 \\
\hline & $117.5-177.5$ & 182 & 47.2 \\
\hline & $178-250$ & 112 & 29 \\
\hline & $>250$ & 36 & 9.3 \\
\hline \multirow[t]{3}{*}{ Educational level } & Diploma & 37 & 9.6 \\
\hline & $\mathrm{BSC}$ & 328 & 85 \\
\hline & MSC & 21 & 5.4 \\
\hline \multirow[t]{6}{*}{ Service years } & $<$ year & 80 & 20.7 \\
\hline & $1-5$ years & 192 & 49.7 \\
\hline & $6-10$ & 40 & 10.4 \\
\hline & $11-15$ & 29 & 7.5 \\
\hline & $16-20$ & 25 & 6.5 \\
\hline & $>20$ & 20 & 5.2 \\
\hline
\end{tabular}

\section{Prevalence of workplace violence among nurses}

The number nurses who experienced workplace violence while working in the referral hospitals of the Amhara Regional state was found to be 103 (26.7\%). The prevalence of physical violence was found to be 62 (60.2 \%) while 41 (39.8\%) of them were facing the psychological violence. Relatively high (59.2 \%) prevalence of work place violence was found among male nurses as compared to females (40.8\%). First degree holder nurses were the most affected group 81 (78.64\%). $38.83 \%$ (40) of the study participants were dissatisfied with the manner how the incident was handled. Among the victims of workplace violence, $36.9 \%$ of them were in need of time off up to one week to recover from the insult.

Those nurses served, 1-5 years were the most frequent victims of workplace violence $41(39.8 \%$ ), followed by those nurses whose service year is less than one year $31(30.09)$. The majority of nurses were attacked by relatives of the patient $62(16.1 \%)$, followed by staff members $28(27.18 \%)$. The largest, 38 (36.9 \%) group of the victims experienced the violence between 13:00 and 17:59 h (Table 2).

Majority 54(52.9\%) of the attackers faced no action from anyone for the unacceptable act while 27 (26.5\%)
Table 2 Prevalence of Workplace Violence among Nurses Working in the Referral Hospitals of Amhara Regional State, Ethiopia. $2015(n=386)$

\begin{tabular}{|c|c|c|}
\hline Variables & & Number (\%) \\
\hline \multirow[t]{2}{*}{ Sex } & Male & $61(59.2)$ \\
\hline & Female & $42(40.8)$ \\
\hline \multirow[t]{4}{*}{ Age } & $18-29$ & $71(68.9)$ \\
\hline & $30-39$ & 16(15.5) \\
\hline & $40-49$ & 11(10.6) \\
\hline & $>50$ & $5(4.85)$ \\
\hline \multirow[t]{3}{*}{ Marital status } & Single & $81(78.6)$ \\
\hline & Married & 16(15.5) \\
\hline & Separated & $6(5.8)$ \\
\hline \multirow[t]{3}{*}{ Educational level } & Diploma & $17(16.5)$ \\
\hline & $\mathrm{BSC}$ & $81(78.65$ \\
\hline & MSC & $5(4.85)$ \\
\hline \multirow[t]{6}{*}{ Service year } & $<1$ year & $31(30.1)$ \\
\hline & 1-5years & $41(39.8) 4.9)$ \\
\hline & 6-10years & $5(4.9)$ \\
\hline & 11-15years & $10(9.7)$ \\
\hline & 16-20years & $6(5.8)$ \\
\hline & $>20$ years & $10(9.7)$ \\
\hline \multirow[t]{4}{*}{ Monthly Income \$USD } & $<117.5$ & $28(27.2)$ \\
\hline & $117.5-177.5$ & $34(33)$ \\
\hline & $178-250$ & $30(29.1)$ \\
\hline & $>250$ & $11(10.67)$ \\
\hline \multirow[t]{3}{*}{ Number of staff } & $1-5$ staff & $74(71.8)$ \\
\hline & $6-10$ staff & $27(26.2)$ \\
\hline & $>11$ & $2(1.9)$ \\
\hline \multirow[t]{4}{*}{ Attackers } & Relatives of the patients & $62(60.2)$ \\
\hline & staff & $28(27.18)$ \\
\hline & Patient & $12(11.65)$ \\
\hline & Manager & $1(0.97)$ \\
\hline
\end{tabular}

aggressors experience the consequences, and 22 (21.36 \%) participants didn't know whether measures were taken.

Factors associated with workplace violence among nurses In the multivariate logistic regression analysis being age 18-39 (AOR; 0.324, 95 CI: 0.115, 0.919), small number of staff in the same shift (AOR; 2.024, $95 \%$ CI: 1.120, 3.658), working in male ward (AOR; 7.918, $95 \% \mathrm{CI}$ : $4.012,15.626$ ), history of workplace violence (AOR ; $0.270,95 \%$ CI: 0.120,0.610), marital status being single (AOR; 9.153, $95 \%$ CI: 3.593, 13.321) and separated/ widowed (AOR; 7.914 95 \% CI: 2.036, 9.763) were suggestive of being independent predictors of workplace violence (Table 3 ). 
Table 3 Simple and multiple logistic regression analysis of factors associated with Workplace Violence among Nurses working in the Referral Hospitals of Amhara Regional State, Ethiopia. 2015 ( $n=386)$

\begin{tabular}{|c|c|c|c|c|c|c|}
\hline \multirow[t]{2}{*}{ Variable } & & \multicolumn{2}{|c|}{ WPV } & \multicolumn{2}{|c|}{ Odds Ratio with $95 \% \mathrm{Cl}$} & \multirow[t]{2}{*}{$P$ value } \\
\hline & & Yes & No & $\mathrm{COR}$ & $\mathrm{AOR}$ & \\
\hline \multirow[t]{2}{*}{ Age } & $18-39$ & 87 & 259 & $0.504(0.25,0.99)^{*}$ & $0.324(0.11,0.91)$ & 0.034 \\
\hline & $40-55$ & 16 & 24 & 1 & 1 & \\
\hline \multirow[t]{2}{*}{ Number of staff in the same shift } & $1-5$ & 74 & 150 & $2.26(1.38,3.68)^{*}$ & $2.024(1.12,3.65)$ & 0.020 \\
\hline & $>5$ & 29 & 133 & 1 & 1 & \\
\hline \multirow[t]{2}{*}{ Working in the night shift } & Yes & 72 & 173 & $1.47(0.910,2.39)$ & $1.788(0.99,3.21)$ & 0.053 \\
\hline & No & 31 & 110 & 1 & 1 & \\
\hline \multirow[t]{2}{*}{ Waiting long time to receive care } & Yes & 54 & 95 & $2.18(1.379,3.45)^{*}$ & $1.20(0.61,2.36)$ & 0.57 \\
\hline & No & 49 & 188 & 1 & 1 & \\
\hline \multirow[t]{2}{*}{ Work safety training } & Yes & 39 & 98 & $1.16(0.72,1.89)$ & $1.19(0.63,2.25)$ & 0.57 \\
\hline & No & 64 & 185 & 1 & 1 & \\
\hline \multirow[t]{2}{*}{ sex } & Male & 61 & 159 & $1.13(0.71,1.79)$ & $1.36(0.68,2.72)$ & 0.38 \\
\hline & Female & 42 & 124 & 1 & 1 & \\
\hline \multirow[t]{2}{*}{ Service year } & $6 \mathrm{~m}-10$ years & 87 & 254 & $0.62(0.32,1.19)$ & $1.08(0.28,4.06)$ & 0.90 \\
\hline & 11-55years & 16 & 29 & 1 & 1 & \\
\hline \multirow[t]{2}{*}{ Educational level } & $\mathrm{BSC}$ & 81 & 245 & $0.57(0.32,1.02)$ & $1.11(0.48,2.57)$ & 0.80 \\
\hline & Others & 22 & 38 & 1 & 1 & \\
\hline \multirow[t]{2}{*}{ Working in male ward } & Yes & 34 & 82 & $1.21(0.74,1.96)$ & $7.92(4.01,15.62)$ & 0.001 \\
\hline & No & 69 & 201 & 1 & 1 & \\
\hline \multirow[t]{2}{*}{ History of workplace violence } & Yes & 13 & 57 & $0.57(0.29,1.09)^{*}$ & $0.27(0.12,0.61)$ & 0.002 \\
\hline & No & 90 & 226 & 1 & 1 & \\
\hline \multirow[t]{3}{*}{ Marital status } & Single & 81 & 166 & $3.11(1.72,5.63)^{*}$ & $9.15(3.59,13.32)$ & 0.001 \\
\hline & Separated/widowed & 6 & 15 & $2.55(0.86,7.53)$ & $7.914(2.036,9.763)$ & 0.003 \\
\hline & Married & 16 & 102 & 1 & 1 & \\
\hline \multirow[t]{2}{*}{ Working with } & Physical disabled & 80 & 169 & $2.34(1.39,3.95)^{*}$ & $1.64(0.88,3.06)$ & 0.115 \\
\hline & Terminally ill patients & 23 & 144 & 1 & 1 & \\
\hline
\end{tabular}

${ }^{*}$ significantly associated at $P$-value $<0.005$

\section{Discussion}

Workplace violence is a major problem in the health sector for health professionals. This study showed that the prevalence of workplace violence among nurses working in the Amhara National Regional State was $26.7 \%$. This is higher than the finding of the previous study, which was done in Oromia National Regional State of Ethiopia [13]. This could be due to differences in the setting of the study.

The prevalence of work place violence in the current study was higher when compared with the findings in USA $25 \%$ [14], Palestine $20.8 \%$ [15], Iran $19 \%$ [16], and Hong Kong $18 \%$ [17]. These may be due to socio economic differences between the countries. This issue can directly expose health care professionals for workplace violence as there is mismatch between health care service need and health care delivery in resource limited countries like Ethiopia. These results in dissatisfaction of health care service consumers in the health care organization so this can lead to workplace violence for health care professionals. Other possible reason can be the difference of the service users in the study areas. In the Amhara National Regional State most of the service users are from the rural community who are not familiarized with the hospital environment, particularly they didn't know the rooms where to go for each health care services. This will result in unsuccessfulness to get appropriate health care service. This will bring anger from the community side which will definitely exposed nurses for workplace violence more frequently.

In this particular study, the odds of workplace violence among nurses who were single [(AOR; 9.153, $95 \%$ CI: 3.593, 13.321) and separated or widowed (AOR; 7.914 95 \% CI: 2.036, 9.763) were nearly 9 and 8 times more likely to have workplace violence as compared to those nurses whose marital status were married respectively. This is in agreement with a study done in Egypt [16]. 
Moreover, the odds of workplace violence among nurses with 1-5 number of staff during the same working shift were 2 times higher as compared to those nurses who had $>11$ number of staff during the same working shift(AOR; 2.024, 95 \% CI: 1.120, 3.658). This is because when the number of nurses is low in a given shift then patient care and safety could be delayed in the hospital which may results in irritation from the hospital user side so that workplace violence will occur.

Additionally, workplace violence was more likely to be occurred among nurses who were working in the male ward. The odds of workplace violence among nurses who were working in male ward were nearly 8 times higher as compared to nurses who were not work in the male ward (AOR; 7.918, 95 \% CI: 4.012, 15.626). This may be due to the fact that males are more aggressive as compared to females. Therefore, those nurses who were assigned in male ward may experience workplace violence more frequently.

Furthermore, the chance of workplace violence among nurses who had history of workplace violence were $88 \%$ less likely to have workplace violence as compared to those nurses who didn't have history of workplace violence (AOR; 0.270,95 \% CI: 0.120,0.610). This may be due fact that, nurses who encountered workplace violence before can develop violence prevention strategy. This is finding is in agreement with a study done in New South Wales [18].

Moreover, nurses who were in the age range of 18-39 were $67.6 \%$ less likely to encountered workplace violence as compared to those nurses who were in the age range of 40-55 (AOR; 0.324, 95 CI: 0.115, 0.919). The reason might be young nurses become effective towards the provision of successful patient care which will definitely decrease the occurrence of workplace violence.

This study has the following limitation. Since the study was cross-sectional, it does not confirm definitive cause and effect relationship. Furthermore, the study may prone to reporting and recall bias.

\section{Conclusion}

In conclusion, this study found that there is high prevalence of workplace violence among nurses working in the referral hospitals of Amhara Regional state. Age, number of staff in the same work shift, working in male ward, history of workplace violence and marital status were the factors independently associated with workplace violence. Creating a prevention strategy involving hospital management body, staff nurses and representatives from nursing association is recommended.

\section{Abbreviations}

BJS, Bureau of Justice and Statistics; BL, Bureau of Labor; NCUS, National Crime Victimization Survey; USA, United States of America; WDR, World Development Report; WHO, World Health Organizations; WPV, workplace violence.

\section{Acknowledgements}

We are highly indebted to acknowledge the study participants who actively participated in this research. Our gratitude also goes to the University of Gondar for providing ethical clearance.

\section{Funding}

The University of Gondar covered the data collector payment. However, the funders had no role in study design, data collection and analysis, decision to publish, or preparation of the manuscript.

\section{Availability of data and materials}

All relevant data were within the manuscript.

\section{Authors' contributions}

BT carried out the study starting from conception, analysis and interpretation of data and drafting of the manuscript. AA participated in data analysis and interpretation of the finding. BB participated in data analysis, interpretation and in critical review of the manuscript. MM participated in reviewing, data analysis, commenting on the drafting manuscript. DZ participated in reviewing, data analysis, commenting on the manuscript. BAD participated in data analysis, interpretation and critical review of the manuscript. All authors read and approved the final draft of the manuscript.

\section{Authors' information}

1. Bewket is Lecturer at the department Nursing, College of Medicine and Health Sciences at University of Gondar, Ethiopia. He has a Bachelor of Science Degree in Nursing, MSc in emergency medicine and critical care nursing Specialization

2. Akililu is internist, Emergency Physician and Associate professor in the department Emergency Medicine, School of Medicine, Addis Ababa University, Ethiopia.

3. Berhanu is Lecturer at the department Nursing, College of Medicine and Health Sciences at University of Gondar, Ethiopia. He has a Bachelor of Science Degree in Nursing, MSc in public health and Psychiatry

Specialization.

4. Mengistu is Lecturer at the department Nursing, College of Medicine and Health Sciences at University of Gondar, Ethiopia. He has a Bachelor of Science Degree in Nursing, MSc in pediatrics and child health nursing Specialization

5. Degefaye is Lecturer at the department Nursing, College of Medicine and Health Sciences at University of Gondar, Ethiopia. He has a Bachelor of Science Degree in Nursing, MSc in infectious disease and HIV medicine. 6. Berihun is Assistant Professor at the department of Biostatistics and Epidemiology, Institute of Public Health, College of Medicine and Health Sciences at University of Gondar, Ethiopia. He has a Bachelor of Science Degree in Nursing, MSc in Adult Health Nursing, Masters of Public Health in Biostatistics and Epidemiology Specialization.

\section{Competing interests}

The authors declare that they have no competing interests.

\section{Consent for publication \\ Not applicable.}

\section{Ethical approval and consent to participate}

Ethical clearance was obtained from the Institutional Review Board (IRB) of the University of Gondar, prior to commencement of the data collection. After discussing the purpose and aim of the study, permission was obtained from the administrator's office of the study hospitals. Participants were informed about the purpose of the study and written consent was obtained before conducting the data collection.

\section{Author details}

${ }^{1}$ University of Gondar, College of Medicine and Health Science, School of Nursing, P.O. Box: 196, Gondar, Northwest Ethiopia. ${ }^{2}$ Department of Emergency Medicine, School of Medicine, College of Health Sciences, Addis Ababa University, 11706 Addis Ababa, Ethiopia. ${ }^{3}$ Department of Epidemiology and Biostatistics, Institute of Public Health, College of Medicine and Health Sciences, University of Gondar, P.O. Box: 196, Gondar, Northwest Ethiopia. 
Received: 29 January 2016 Accepted: 7 June 2016

\section{Published online: 08 July 2016}

\section{References}

1. International Labour Organization, International Council of Nurses, World Health Organization, Public Services International. Work place violence 2002.

2. National Coalition Against Domestic Violence. Facts about domestic violence and psychological abuse. 2015. www.ncadv.org.

3. Vittorio $\mathrm{d}$. Workplace violence in the health sector: Relationship between work stress and workplace violence in the health sector. 2003.

4. OSHA. Guidelines for preventing workplace violence for healthcare and social service workers. Washington DC: U.S. Department of Labor Occupational Safety and Health Administration; 2015.

5. Findorff M, McGovern P, Wall M, Gerberich S. Reporting violence to a health care employer: a cross-sectional study. AAOHN J. 2005:53(9):399-406.

6. Gerberich SG, Church TR, McGovern PM, Hansen HE, Nachreiner NM, Geisser MS, et al. An epidemiological study of the magnitude and consequences of work related violence: the Minn Nurs' Stud. 2004;61(6):495-503.

7. Gates DM, Gillespie GL, Succop P. Violence against nurses and its impact on stress and productivity. 2011;29(2):59-66.

8. Findorff-Dennis MJ, McGovern PM, Bull M, Hung J. Work related assaults. The impact on victims. AAOHN J. 1999:47(10):456-65.

9. Abou-E, Gilany E, Abd E, Sayed H, Sayed R. Workplace Violence Against Emergency Versus Non-Emergency Nurses in Mansoura University Hospitals, Egypt. J Interpers Violence. 2014. Epub 2014/06/28.

10. Khalil D. Levels of violence among nurses in Cape Town public hospitals. Nurs Forum. 2009;44(3):207-17.

11. Steinman S. Workplace violence in the health sector. 2003.

12. Isinta M, Tsinanga J. Workplace violence: a growing challenge to health care workers in emergency departments. 2008.

13. Likassa T, Jira C, Woudineh H/M. Assessment of the Prevalence and Predictors of Workplace Violence Against Nurses Working in Referral Hospitals of Oromia Regional State, Ethiopia. Int J Emerg Trends Sci Technol. 2014;1(4):566-571.

14. Gacki-Smith J, Juarez A, Boyett L, Homeyer C, Robinson L, MacLean S. Violence against nurses working in US emergency departments. J Nurs Adm. 2009:39(7-8):340-9. Epub 2009/07/31.

15. Kitaneh M, Hamdan M. Workplace violence against physicians and nurses in Palestinian public hospitals: a cross-sectional study. BMC Health Serv Res. 2012;12:469. Epub 2012/12/22.

16. Abou-EIWafa HS, El-Gilany AH, Abd-El-Raouf SE, Abd-Elmouty S, El-Sayed Rel S. Workplace violence against emergency versus non-emergency nurses in Mansoura university hospitals, Egypt. J Interpers Violence. 2015;30(5):857-72. Epub 2014/06/28

17. Kwok RP, Law YK, Li KE, Ng YC, Cheung MH, Fung VK, et al. Prevalence of workplace violence against nurses in Hong Kong. Hong Kong Med J. 2006; 12(1):6-9. Epub 2006/02/24

18. Cashmore AW, Indig D, Hampton SE, Hegney DG, Jalaludin BB. Workplace violence in a large correctional health service in New South Wales, BMC health services research. 2012.

\section{Submit your next manuscript to BioMed Central and we will help you at every step:}

- We accept pre-submission inquiries

- Our selector tool helps you to find the most relevant journal

- We provide round the clock customer support

- Convenient online submission

- Thorough peer review

- Inclusion in PubMed and all major indexing services

- Maximum visibility for your research

Submit your manuscript at www.biomedcentral.com/submit
Biomed Central 